\title{
Critical Thinking and Reasoning for Information Systems Students
}

\section{Theda Thomas, Tim Davis and Alanah Kazlauskas ACU National, Australia}

\section{t.thomas@patrick.acu.edu.au t.davis@mcauley.acu.edu.au, a.kazlauskas@mackillop.acu.edu.au}

\begin{abstract}
It is important for higher education institutions to produce Information Systems graduates who can think and solve problems effectively. This paper is a rich description of the first cycle in an action research project defined to investigate the effectiveness of using a specially developed unit in the first year of an Information Systems course in order to facilitate the enhancement of students' critical thinking and reasoning skills. Introduced for the first time in Semester 2, 2003, the unit does not try to teach thinking and reasoning skills in isolation but shows how they can be applied within the field of Information Systems in a direct way. This paper describes the unit content together with qualitative comments depicting the students' and the lecturers' experiences with the unit and an analysis of and reflection on what worked and what did not. The skills covered in this unit should then be able to be applied in units offered elsewhere in the course.
\end{abstract}

Keywords: information systems education, critical thinking, problem solving

\section{Introduction}

The new IS2002 curriculum has strong analytical and critical thinking skills second on their list of four characteristics of an Information Systems (IS) graduate. The authors say that these skills have been integrated into the new curriculum and need to be embedded into all units. (Gorgone et al., 2002, p.7)

The curriculum expands this to say:

"IS professionals must have strong analytical and critical thinking skills. Students must therefore:

- Be problem solvers and critical thinkers

- Use systems concepts for understanding and framing problems

- $\quad$ Be capable of applying both traditional and new concepts and skills

- $\quad$ Understand that a system consists of people, procedures, hardware, software and

Material published as part of this journal, either on-line or in print, is copyrighted by Informing Science. Permission to make digital or paper copy of part or all of these works for personal or classroom use is granted without fee provided that the copies are not made or distributed for profit or commercial advantage AND that copies 1) bear this notice in full and 2) give the full citation on the first page. It is permissible to abstract these works so long as credit is given. To copy in all other cases or to republish or to post on a server or to redistribute to lists requires specific permission from the publisher at Publisher@InformingScience.org data." (Gorgone et al., 2002, p.6)

While as academics we often say that we need to develop students' thinking skills, in practice we often only teach in a structured, controlled way. Students often find it difficult to make the transition from the controlled envi- 
ronment of the university to the real world environment, which demands creative and unstructured thinking (Goyal, 1995/1996, p.135).

The Australian government's Ministerial Discussion Paper on Higher Education at the Crossroads (Nelson, 2002, p.14) describes the need for "a system that produces graduates who can think critically and have adaptable skills sets as well as technical expertise". The paper indicates that too often graduates leave university without being able to think logically, write clearly or speak coherently. Further, the Graduate Skills Assessment evaluates graduates' abilities in four areas, namely critical thinking, problem solving, interpersonal understandings and written communication. These are considered generic skills that need to be developed in undergraduate degrees.

It was these needs that led to the incorporation of a new unit into the first year of ACU National's IS course, namely a unit in reasoning and critical thinking for IS professionals. This paper describes why it was felt necessary to have a separate unit in the first year and then presents a rich description of the first cycle in an action research project that is investigating the effectiveness of the teaching and learning of these skills.

Action research was selected as the methodology for conducting our research. Action research lends itself to use in work situations, such as this introduction of a new unit where the researcher is also recognized as an agent of change. It also openly recognizes the partnership that exists between the researcher (lecturers) and the client (students). The action research cycle is consistent with that of the learning cycle described by Kolb (1984) and its use is supported by Schön's argument that systematic reflection is an effective way for practitioners (lecturers) to learn.

\section{Methods of Improving Students' Thinking Skills}

There is considerable debate as to how critical thinking and reasoning skills should be taught (Smith, 1992). In considering how to incorporate the skills into the curriculum, many feel that they should be integrated into normal teaching practice for all units and this is what is suggested by the new IS2002 curriculum (Gorgone et al., 2002). This, however, causes problems for lecturers who may not understand how to teach these skills. What often happens under these circumstances is that the lecturer assumes that the students have the skills rather than specifically helping the students to develop them. A 'sink or swim' situation develops where many students often sink. A second approach says that thinking skills should be taught as a separate unit. However, this gives rise to the problem that students sometimes cannot transfer the skills taught in one unit to other units.

ACU National is a national university and the Sub-Faculty of Business and Informatics, offers the Bachelor of Information Systems in three separate locations, namely, Sydney, Melbourne and Brisbane. The two issues that required consideration by academic staff at each of these locations were firstly, how to incorporate teaching of the skills into a curriculum and secondly, whether or not to focus on the discipline area or teach the skills in a more generic way. The first approach to teaching critical thinking and reasoning skills would be to teach the skills in a generic form without linking them to a particular subject or discipline area. This approach would have supported the notion that these skills are required across a broad spectrum of life experiences and would therefore provide certain life-long learning opportunities. However, taking this approach could be seen to be problematic from the students' perspective depending on their ability to relate the learning experience to the broader context. The second approach would be to teach the skills directly relating them to the discipline area. Again, this gives rise to the problem that students sometimes have difficulty transferring the skills taught with a discipline focus to a broader context.

The Sub-Faculty decided to use a separate unit to teach thinking skills and to link the teaching of the skills to the development of the IS professional, thus allowing students to develop these think- 
ing skills within the IS field. This new unit is called Reasoning and Critical Thinking for IS Professionals. The unit is a first year unit. The intention is that the skills learnt in this unit will be applied in other units that are taught concurrently or in later years.

The three authors were each involved in the teaching of the unit at these three campuses. Each brought their own flavor to the teaching, although a common set of notes was used and some of the assessments were common. In Melbourne and Sydney the unit was taught with 2 one-hour lecture periods and 1 two-hour tutorial session. The tutorials in Melbourne took place in a computer laboratory, although the computers were seldom used, except to get documents from WebCT. In Sydney the tutorials took place in a classroom or a computer laboratory as determined by the lecturer on a weekly basis. In Brisbane the unit was taught using 1 two-hour lecture and 2 one-hour tutorials. One hour was given to a communications expert who taught the students how to communicate their reasoning in written and oral form with the second hour being used for discussion and practical exercises of the material presented in lectures. Both tutorials took place in classrooms.

Student cohorts differed significantly between the campuses. With respect to the proportion of international students, the overall cohort of our students appears to differ significantly from both ACU National's profile as well as the national profile. Total student enrolments for the Reasoning and Critical Thinking for IS Professionals unit across all three campuses was 122 . However, as this paper is based in part on the action research project linked to this unit, the data presented is limited to the 85 students who agreed to participate in that project.

Table 1 provides details of the gender distribution for the unit across all campuses. Although there is significant cross campus variation, the overall gender mix for our students undertaking information systems (information technology) is not inconsistent with that of the $23.5 \%$ female and $76.5 \%$ male mix undertaking a similar program as reported in the Australian Government's Students 2003 (First Half Year): Selected Higher Education Statistics.

Table 1: Student population by location and gender

Table 2 provides details of the domestic versus international student makeup. The international students are of interest as almost all of them have English as a second language and this presented some challenges. There is a significant cross campus variation with Sydney's population having been comprised of $54 \%$ international students and Brisbane having been

\begin{tabular}{|c|c|c|c|c|c|}
\cline { 2 - 5 } \multicolumn{1}{c|}{} & \multicolumn{2}{c|}{ Female } & \multicolumn{2}{c|}{ Male } & \multicolumn{1}{c}{} \\
\hline Location & $\mathbf{n}=$ & $\%$ & $\mathbf{n}=$ & $\%$ & Total \\
\hline Sydney & 8 & $16.0 \%$ & 42 & $84.0 \%$ & 50 \\
\hline Melbourne & 7 & $41.2 \%$ & 10 & $58.8 \%$ & 17 \\
\hline Brisbane & 0 & $0.0 \%$ & 18 & $100 \%$ & 18 \\
\hline Total & 15 & $17.6 \%$ & 70 & $82.4 \%$ & 85 \\
\hline
\end{tabular}

Table 2: Student population by location and domestic/international comprised of $100 \%$ domestic students. Of particular interest is that the aggregate level of $34.1 \%$ for international students, the student population undertaking this unit appears to be well above ACU National's overall international student population of $8.9 \%$ as well as Australia's higher education sector overall interna- 
tional student population of $18.3 \%$ as reported in the Australian Government's Students 2003 (First Half Year): Selected Higher Education Statistics.

One additional interesting finding is that while $65.9 \%$ of the student population is domestic, only $45.9 \%$ of the domestic population claim English as their only language and that $54.1 \%$ were multi-lingual.

As mentioned previously, this research is being undertaken as an action research project. The reflections of the students and the lecturers have been used to inform and modify the teaching and learning of the unit. This paper does not propose to prove whether this method of teaching these skills is effective or not, or whether students are able to transfer the skills learnt to other units. The paper describes what was taught in the unit and gives some indication of what did and did not work according to the reflections of the lecturers and students. The methods of teaching and learning can then be applied by other academics to the teaching of their own units or within their area of specialization. Further research will be done in future years to determine if the skills covered in this unit are used effectively in later years of the degree program.

\section{Objectives for the Reasoning and Critical Thinking Unit}

As mentioned before, the IS2002 curriculum suggests that the way to develop strong analytical and critical thinking skills is to embed these into IS courses. The objectives for the unit "Reasoning and Critical Thinking for IS Professionals" tries to help students to learn the skills that were described in the introductory paragraph.

The objectives of the unit given in the unit outline are (ACU National, 2002):

"On completion of this unit students should be able to:

(i) understand and explain reasoning, critical thinking and problem solving;

(ii) apply the principles of critical thinking;

(iii) develop and apply relevant skills to problems related to information systems, particularly algorithm development;

(iv) demonstrate an understanding of the application of reasoning and thinking in the information systems discipline."

The suggested types of thinking that should be covered in the unit are: strategic, critical, analytical, systems, creative, consequential and reflective. These thinking skills will then be able to be applied in writing, analysis, systems development, programming and algorithm design.

\section{Application of the Objectives}

An action research project consists of the planning, implementation, analysis and reflection phases. During the planning phase, the current IS literature was studied in order to plan how the unit should be taught. The unit was divided into six parts, namely:

- An overview of different types of thinking,

- Analytical and critical thinking for algorithm development,

- Reasoning and critical thinking,

- $\quad$ Systems thinking,

- $\quad$ Problem solving, and

- $\quad$ Reflective and ethical thinking. 
Prior to the commencement of the semester, notes and exercises were developed and appropriate readings identified to help students to learn these skills. The action research project then went from the planning phase into implementation. In the discussion that follows, each of the six areas will be discussed together with some practical examples and ideas as to how the skills were practiced. For the purposes of this article, students' and lecturers' analysis and comments are included where appropriate.

\section{An Overview of Different Types of Thinking}

This introductory section of the curriculum was used to expand the students' view of thinking skills and to give them an idea about the different types of thinking in an IS context. The students were introduced to strategic, critical, analytical, systems, creative, consequential and reflective thinking, and given examples of how this type of thinking might be used in IS.

Consequential thinking, for example, was explained as the ability to think of the different things that might happen depending on what path they choose to follow. This type of thinking helps to form a clear understanding of the consequences of choices and to recognize cause and affect relationships. It was shown to be useful when considering alternative solutions for developing information systems as well as making important decisions and life choices.

Small exercises helped the students to see how the different types of thinking could be used in IS. Students were asked to analyze an article by Paul and Elder (2002) on teaching students how to study and learn, in order to determine how the different types of thinking were used in each of the ideas that were proposed in the article. The idea was emphasized that no one type of thinking is sufficient and that the different types work together to give a person good thinking skills.

One of the students commented on this section of the course in their reflection on the unit, saying: "The aspect of the unit that has helped me the most in my studies was probably learning and understanding the different types of thinking that can be used and how you can benefit from using these different types of thinking together. This helps me to understand what thinking works well together and what type of thinking people use in different situations."

The importance of being able to express one's reasoning was emphasized. As another of the students said: "One of the key points of the subject was 'you may be a great thinker, but it is just as important to be good at expressing your ideas" ". In Brisbane, the language expert helped the students with this aspect. In Melbourne and Sydney, the IS lecturers spent some time dealing with this issue as well.

\section{Analytical and Critical Thinking for Algorithm Development}

In this section, the students were shown how to break down a problem into manageable pieces and then put this into pseudocode and flowcharts. They were also taught how to create test data and critically evaluate their own and other people's algorithms. In Melbourne and Sydney, the students commented on its usefulness to them in programming. For example, one of the students, said: "The aspects which have helped me the most in my studies would easily be the critical thinking and analytical thinking involved in the unit. This has helped me a great deal during the year, mainly with programming techniques. More than anything, it has helped me to analyze the problem and fix it." In Sydney, the programming lecturer was interested in and so kept informed about the work on algorithm development that was being done in Reasoning and Critical Thinking for IS Professionals.

In Brisbane, the material on algorithm development and testing was presented in the programming unit as well as Reasoning and Critical Thinking for IS Professionals. In the programming unit, the material was purposefully more comprehensive than in this unit. For that reason, stu- 
dents felt the material in this unit was a duplication of what they experienced in the programming unit and a waste of their time. However, an interesting phenomenon occurred in the final examination for the two units. In the programming exam, the lecturer reported that many students did not make any form of a reasonable attempt to address the algorithm design and testing problem presented. However, approximately 87\% (34 of 39) students attempted the algorithm problem set out in the Reasoning and Critical Thinking for IS Professionals exam. Of these students, 75.5\% (25 of 34) did so acquiring, on average, greater than $65 \%$ of the marks possible.

It is interesting to speculate on why the students made the attempt in the one unit and not in the other. Perhaps the students are loath to be called poor thinkers, but are happy to throw in the towel and not attempt to design a program or do maintenance on someone else's. There does seem to be some benefit, however, in pointing out to students that they are using different types of thinking skills while designing and debugging their programs. The transfer of the skills will need to receive more attention in future.

\section{Reasoning and Critical Thinking}

\section{Structuring arguments}

In this section, students were firstly introduced to the idea of making claims and structuring arguments. This was based on the work of Allen (1997) and Jones (1997). This part of the work involved taking the written arguments of others and analyzing them to determine how they were structured. Sometimes the examples given were not arguments at all and the students had to realize this.

The students' ability to reason and explain their reasoning in a structured way was practiced in varying degrees using discussions on WebCT and Unilinks, a recently developed environment for virtual collaboration. The lecturer would put up a topic for discussion and the students had to take a view on that discussion topic and try to add something new to the discussion. Students were not allowed to repeat what anyone before them had said before. Students were encouraged to take a stand on some controversial topic and to show why they were correct and/or why the other side of the topic was wrong. "Conflict is the heart of all drama, a major tool for capturing interest and attention. If students are to learn and master the procedures and skills required for managing intellectual conflicts constructively, they must do so in the classroom" (Johnson, Johnson \& Smith, 1997).

In Brisbane, these discussions were started in Week 2 (before learning about structuring arguments). They were given a new topic every two weeks. In Melbourne the students were only given three topics through the semester. In Sydney, there was only one online discussion.

The first topic, used in Brisbane, was "Many arguments have been put forward to support the continued criminalization of marijuana use. The same arguments apply to the use of alcohol and therefore, alcohol should be criminalized as well." As this was the first discussion topic submission, parameters were not set on the size and level of detail that the submission should contain. Student submissions to the discussion topic averaged over 500 words and were presented in a standard essay-type format. Positions taken and arguments presented tended to be poorly structured and based more on emotive persuasion than reasoned logic. The last topic was "The topic for this week deals with the use of the Internet (i.e. WebCT) for presentation and assessment of educational material. Increasingly, universities are encouraging the use of Internet-based presentation and assessment of material. The justification of this encouragement comes from very different perspectives. For this week's topic, you are required to write a short paragraph $(<150$ words) that argues a particular position regarding use of the Internet for presentation and/or assessment of educational material. You are then required (in the same submission) to put your 
argument in 'standard form' followed by a short statement on the type of argument you have used." Although the students were allowed to develop their submission in the same manner as previous discussion topics, this submission had specific guidelines set on its size and form. Of particular interest in this instance was the anecdotal evidence that students were beginning to develop their mental arguments in standard argumentation form (a sequence of simple statements as premises followed by a conclusion) and then expand the premises and conclusion into the required paragraph. In the individual student submissions where the required standard argumentation form preceded the explanation paragraph, the explanation paragraph was significantly more complete and well formed. However, in the individual student submissions where the standard argumentation form was presented in the submission following the required explanation paragraph, the explanation paragraph was not as complete and well formed.

A complete analysis of how the discussions were used and their effectiveness is outside the scope of this paper, but some of the students' comments on it are interesting:

"There have been a number of aspects through which this unit has helped me to develop my ability to write and develop arguments better. One of these aspects was the exercise involving the discussion postings, which helped me to learn to defend my viewpoint and argue with others. Another of these aspects could be detailed study of claims involved with this unit, which developed a better understanding of claims and arguments and helped me to write them effectively."

"The discussion groups were great in being able to practice putting forward my ideas and critically thinking when reading others work. In the future, in the workforce, I most look forward to being able to express my ideas well and being an analytical and critical thinker."

"The aspects that have helped me with my day-to-day life, have been my ability to see other people's point of view and look at it using the different styles of thinking to better understand a person. I have been capable of communicating my opinion in a more constructed manner, to better represent my view and convey it."

"The unit has had a great impact on the way I write and develop my arguments. I no longer just look at an argument and jump right into answering it. I now put a great deal of thought into the ways that I will construct my claims, I look at the ways that they should interact in the best way possible in order to develop an argument that is well constructed and answered to the best of my ability."

"I used to have a difficulty to write a long sentence, especially writing an essay. Now I am not scared of writing even though my writing is still bad. The important thing to me is I enjoy reading and writing in English. It's a big change."

On the negative side, one student wrote, "I feel that the claims diagrams were a waste of time and could not see the relevance of it, as I could not understand how it related to information systems at all." It was interesting to note that the same student said later in her reflection "I feel that this unit has helped me with by ability to write and develop arguments as this unit has helped me to understand how arguments can be set out and how to make arguments stronger just by the way that they are set out."

\section{Logical and critical thinking}

In this section of the unit, the students were initially asked to try to answer some critical thinking questions. These were adapted from Bowles (n.d.) and contained such questions as:

Mr. Baker, Mr. Butcher and Mr. Builder are a baker, a butcher and a builder, but not in that order. No man has the same profession as his name. Mr. Builder is not a butcher. Which of the following is/are true? 
I) Mr. Baker is a butcher.

II) Mr. Butcher is a baker.

III) Mr. Builder is a baker.
a. I only
b. II only
c. III only
d. I and II only
e. I and III only.

The students did not do particularly well on the exercises. They were then taught methods of logical thinking using induction and deduction and given appropriate exercises. Following this they went back to these exercises and were asked to describe what they had done incorrectly and say why the right answer was correct.

It soon became clear that some of the questions were particularly difficult for students for whom English was a second language. The question:

"Some zings are zangs. Some zangs are zongs. Which of the following can we conclude for sure?"

had these second language students searching in their dictionaries for the words, "zings", "zangs" and "zongs".

Similarly blank looks abounded when students were asked to draw the structure of the following argument

Delphina's triple chocolate A-bombe, which is extremely delicious, is apt to be high in calories and fat. Most really delicious desserts are very high in calories and fat.

International students found the nature and delivery of this unit very different from any study they had undertaken previously. One student said that she kept her friends in China informed about "the different things I am doing here."

The students seemed to enjoy these exercises. One older international student commented that the continuous flow of small exercises was painful but great to keep students' brains working! "continuous flow of small exercises when we have to 'start thinking' (-) it did pain... $\Rightarrow$ it was great to fresh our brain", Others again commented that these skills would not be useful to them as IS graduates.

Some felt that these exercises were a waste of time. One student, for example said: "Aspects such as claims, reasoning and the others were analysis of sentences were involved. I don't see the relevance between this and a course in I.T. I'm not sure this will be needed in a career involving I.T." The relevance will have to be more carefully suggested in subsequent years.

\section{Systems Thinking}

The students were introduced to the importance of systems thinking and the value of understanding the interaction between the different parts of an IS (including the people involved.) The students were asked to draw Rich Pictures of complex IS situations. An article by Monk and Howard (1998) was used to help students understand the concepts. Group-based tutorials helped the students to apply this knowledge. Rich Pictures originated as part of the Soft Systems Methodology and are usually taught to more mature students. The students in their first year did not seem to 
have too much difficulty in drawing these pictures, although they were sometimes a little short sighted in what they considered relevant. However, some students, especially those who did not have English as their home language, seemed to find it quite daunting.

It was interesting to note that the students who took the leadership roles in these exercises were not usually the same ones that had been involved in previous group work. Some of the students seemed to feel themselves more creative and jumped at the chance of leading the discussion and drawing the diagrams on the butcher paper that had been put up around the classroom.

Some of the students' comments included: "In the future I will try to think more clearly about the problem as a whole. Try to see the full aspect of problems, which can be difficult to do at times" and "This method of thinking (systems thinking) has allowed me to realize more about how things interact with one another. Other times I would have just done something and find out the results when it is done" (brackets provided).

\section{Problem Solving}

The problem solving section concentrated on high-level problem solving rather than solving logic problems. The techniques discussed were some of de Bono's (1985) CoRT thinking program for schools namely:

- $\mathrm{CAF}$ - consider all factors

- $\quad$ PMI - plus, minus and interesting

- Brainstorming - creative thinking

- $\mathrm{C} \& \mathrm{R}$ - looking at consequences and results

- SCAMPER - substitute ideas, combine ideas, adapt ideas, magnify/minify ideas, put ideas to other uses, eliminate ideas and rearrange ideas.

- Evaluating and choosing from alternative solutions

The different thinking skills learnt previously were emphasized during these exercises.

The main problem used was one of how to introduce technology to the voting process in Africa. The students worked in groups and had to consider the issues around voting in Africa (e.g. no electricity, illiteracy, fear of technology) as well as those around voting in general (e.g. privacy, security).

The groups came up with quite disparate solutions to the problem, some of which would not be feasible like having touch screens on mobile lorries traveling around the country. In Sydney, where 8 of the 55 students were female, a "girls only" group who chose to be referred to as "The Minority', were initially reluctant to report their solutions to the group but eventually did so because they perceived their approach to solving the problem as very different from the solutions proposed by the boys' only groups.

\section{Reflective and Ethical Thinking}

Reflective thinking refers to the process of observation of an experience followed by careful consideration of what was done in order to learn from that experience. It was explained that reflective thinking is important so that you don't make the same mistake twice. Students were asked to apply this process to their learning within this unit and it is from these reflections that many of the comments for this article have come.

Thinking ethically was related to different types of thinking. In Brisbane and Melbourne, an article by Wood-Harper, Corder and Byrne (1999) was used to help the students see the relationship 
between systems thinking and ethical thinking in IS development. The article looks at how the ethical views of the different people who will use an information system might be different and even conflicting. This article was used in the second assignment by Brisbane, but was only used in the classroom in Melbourne. A discussion of assignment tasks given to students follows.

\section{Assignments}

Students were given two major assignments. Both assignments required the students to investigate arguments put forward giving two different viewpoints on the same topic. Except for Brisbane, which varied on the second assignment, both assignments were carried out using the same three-week procedure:

- During the first week the students worked on the assignment themselves, preparing a draft version of the assignment;

- In class during the second week, students exchanged assignments and the students evaluated each other's assignments using guidelines given to them by the lecturers; in Sydney this was done anonymously; draft assignments and the comments of other students were returned to students;

- Students reviewed their draft assignment and submitted a final version of the assignment in the third week. Students brought to the review process what they had learnt from their evaluation of other students' work as well as the evaluation of their own work. Students were also required to write a statement indicating and explaining the changes they had made to their draft assignment and why they had chosen not to make changes if their evaluator had suggested ones that they disagreed with.

After reviewing the process used for the first assignment, the second assignment was expanded slightly to include a reflection on what students felt that they had learnt through this experience (using their recently enhanced reflective thinking skills!)

The first assignment was given to the students in Week 2. The students were asked to read two articles, one which reasoned that the Apollo Moon Landings did not occur (Overstreet, 1998) and the other that proposed that they did occur (Yates, n.d.). They were then asked to draw a diagram showing how some of the arguments related to each other. The second question asked students to analyze how the one article refuted an argument given by the other article. The last question tried to get students to incorporate their own ideas by looking for reasons as to why the USA might have faked the moon landings and reasons why their opponents might have suggested that the landings were faked. The last question asked students to take a stance for or against the moon landings and to support their stance with well-thought out arguments. The peer review took place in Week 3 and the final assignment handed in after the modifications had been made.

The second assignment (for Sydney and Melbourne students) investigated the topic of "Honeypots", a means of obtaining knowledge of the techniques of computer hackers by attracting them to a false system. Four articles were given to the students, some of which were articles from newspapers. The students were firstly asked to draw out from the articles all the claims that were made by the authors either for or against the implementation of honeypots. Students were then asked to rearrange those claims into some sort of order, grouping them by topics and rewriting them in their own words. Finally, they were asked to write an argument for or against the use of honeypots and to show how their argument was constructed. The assignment was given to the students in Week 10, peer-reviewed in Week 11 and handed in during Week 12.

This type of assignment proved to be an interesting exercise. Plagiarism is one of the most difficult things to eradicate in first year students' work. On the positive side, this exercise helped them to write in their own words and the final written arguments were generally fairly well structured. 
One of the students commented on how this ability helped him in another subject: "When writing a management essay, I broke down those theories written in the text book into several pieces, reanalyzed them then found the common points and connection between theories that from the different writers... It also helped me structure the whole essay"

Unfortunately those that were poorly structured did not seem to see the relevance of the diagram in showing them their problems. When they had a diagram showing Claim 3 pointing to Claim 14, pointing to Claim 23, pointing back to Claim 6, they were quite happy and did not see this as a problem. Another negative factor was that most of them decided that they did not need to reference the original articles. Our assumption is that they felt that as they had rewritten the claims in their own words and the articles had been specified, this was not necessary.

When asked to comment on the parts of the unit that they found most beneficial, many of them indicated the assignments and, in particular, the peer review process.

Some of their comments were:

"This unit has helped me to be more critical of my own work and to analyze it very carefully."

"What will be a benefit from this subject is the way that I'll now approach doing assignments. Several of the assignments were a bit different to any that I had done previously."

"I like doing this kind of assignments compare to just writing essays. We need to do more research and do more think on claims, consequences, arguments etc. It was very helpful that the assignment was based on 'computer theme'. Because we are Information Systems students I will always prefer doing everything related to Information Technology. Again I would like to express thanks for this kind of assignment as it did improve our reading, thinking and synthesizing ability. I improve my English knowledge and this assignment pushed me to 'do more than I usually do'. That means I spend more time on preparation, reading and especially writing. This is my acknowledgement not complaint."

"The peer assessment process proved an invaluable experience. It allowed for clarification in areas that were unclear or incorrect. It also provided a chance to offer assistance to other students that were having difficulty. In the same way comments from other students could be used to ensure that sufficient detail was provided, ensuring the clarity of the ideas being present. This assignment (about Honeypots) encouraged critical thinking because the questions required that all sides of the topic be considered. The nature of the topic meant that responses did not consist of one right and wrong answer but of many. The transition to the final versions of the assignment required extensive reflection as well as a willingness to accept the ideas of the peers that provided external feedback. ... The invaluable lessons learnt from others led to a greater understanding which would be impossible by any other means."

The second assignment in Brisbane was somewhat different. The first difference was that an article by Wood-Harper, Corder and Byrne (1999) was used in conjunction with MD 703: Primer On Ethical Reasoning with Information Technology (n.d.). After reading these articles, students were required to: a) identify arguments presented by the authors for taking a multi-view approach to the development of information systems; b) develop a diagram representing the different ethical theories presented by the authors and then to select one of the theories, supporting their selection; and c) given a system development task, identify the ethical views that might be taken by each of the stakeholders, identify the possible conflicts in these different views and then support their position on whether or not they would do the task. The second difference was that students were not allowed to share their draft assignments with other students and receive written feedback prior to their actual submission. The result was interesting. There was a drop in the average mark of the second assignment over the first assignment by approximately $12 \%$. While the quality of the responses, particularly the third part of the assignment, was decreased and thus resulted in lower 
marks, the originality of the work submitted was more apparent. Not surprisingly, during the unit's end-of-semester review, students expressed the belief that moderating another student's work was a valuable exercise and should be an expectation for all assignments.

\section{Preliminary Reflection}

\section{Students' Reflections}

At the completion of the unit, students were given the opportunity to participate in a reflective thinking exercise by completing a survey instrument that asked them to reflect on their experience in the unit. The first component of the instrument was comprised of a series of 11 questions where students were asked to respond, not only with their answer to the question, but also their motivation for their response. Whilst the students' reflections were generally very positive, most of the negative criticism came from the structuring of reasoning, critical thinking and logic exercises that the students felt were not IS related. Comments not mentioned before included:

"In reasoning the claims. This is not applicable in real life as I do not know how they are used in outside world. It's like learning English (as a subject)."

"I would say the reasoning part (claims, induction etc) is a bit confusing and I'm not really good on those."

Other students commented on aspects of the algorithm development section of the unit:

"I would expect little bit better coordination between units - for example - pseudocode was part in programming techniques I as well as INFO117 - we can use the time for something else not to duplicate."

During the algorithm design students had been asked to write an algorithm to allow a robot (Robbie) to cross the road where there was an island in the middle of the road. After they were satisfied with their solution, they were asked to send Robbie across to the USA (where they drive on the opposite side of the road) and to see if their algorithm still worked. One of the international students commented:

"Discussing things like Robbie the Robot dies if he crosses the road in USA because these are different rules in different countries when planning is done it will be entirely based upon the circumstances, rules and regulations I feel that I have wasted some time on the Robbie crossing road in the USA.(sic)" It was fairly obvious that the student had missed the whole point of the exercise and its application.

A few of the students claimed that the unit was more difficult than they expected. "I expected this unit to be fairly easy and not much workload at the start of the year. This unit didn't live up to my expectations because in my mind, it was the hardest subject, due to reasons that it required a lot of thinking and different styles of thinking made the subject most difficult (sic)." Another student stated: "I expected that critical thinking would be easy. It was not easy but good in that it is a challenge."

On a positive note, a recurring theme among the International students seemed to be that the unit helped to open their minds. Comments included: "I became an open minded person after studied the unit. Some thing that I come across with wider perspective. But on the other hand more information I get sometime more confusing I have on making decision for the situation(sic)." In a similar vein another said: "Using the thinking can get more and more opinion, the brain is opened, so the argument is very easy to think out, you can choose the strongest arguments against or agree the topic(sic)." Others did know what to think initially: "First, I didn't have a clue what this unit all about. But when it started, I thought it was cool. It is different from other subject (not 
just read material, do assignment, exam). It's more than that. We learn how to improve ourselves."

Other comments from the students indicated that they saw its value in helping them with their studies in other units. "This unit has helped me better analyze questions in test or assignments in other subjects. It also helps me think of more questions to ask the lecturers about the work that I'm doing so that I can get a better idea of what I have to do and how it relates to other things in the unit or other units."

"I have found that the way I think about a problem helps determine the number of possible solutions to a problem. The aspects that have helped me to develop these skills have come from the way I think. Learning about how I think therefore will help me understand how to create solution to the problem. Being able to come up with multiple solutions has helped me in my studies as I have been able to better understand questions and how I should answer them."

Most students seemed to realize the need for continuing to practice their skills, one of them saying: "To improve my reasoning and critical thinking skills, I will continue to use the different styles of thinking and problem solving. By practicing these skills, hopefully I will become an expert in applying the different types of thinking in everyday life, the workplace and my studies." And another "I have learnt to written down my arguments first and plan and think about what I want to say, in order to include everything in the piece of writing."

The second aspect of the survey was a series of 5 statements indicating various ways in which the unit had helped. Using a 5-point Likert Scale from 'Not at all' (1 point) to 'A lot' (5 points), students were asked to respond with their level of agreement to the statement. Table 3 provides the mean and standard deviation for each of the statements.

Table 4 shows the overall positive, neutral and negative commitment of the students to each of the statements. This is based on 'Not at all' and 'Only a little' reflecting a negative or unsupportive response to the statement, 'Average' being a neutral response, and 'Quite a lot' and 'A lot' reflecting a supportive response.

Table 3: Mean and standard deviation for questions using Likert scale

\begin{tabular}{|l|l|c|c|}
\cline { 2 - 4 } & \multicolumn{1}{|c|}{ Statement } & Mean & S.D. \\
\hline Q12 & $\begin{array}{l}\text { I feel that this unit has helped me or will } \\
\text { help me in my studies. }\end{array}$ & 3.82 & 1.01 \\
\hline Q13 & $\begin{array}{l}\text { I feel that this unit has helped me or will } \\
\text { help me in my daily life. }\end{array}$ & 3.21 & 1.01 \\
\hline Q14 & $\begin{array}{l}\text { I feel that his unit will help me when I } \\
\text { get into the IS industry. }\end{array}$ & 3.89 & 1.00 \\
\hline Q15 & $\begin{array}{l}\text { I feel that this unit has helped me or will } \\
\text { help me to express myself better when } \\
\text { reasoning with others. }\end{array}$ & 3.54 & 1.06 \\
\hline Q16 & $\begin{array}{l}\text { I feel that this unit has helped me or will } \\
\text { help me to analyze other people's points } \\
\text { of view in a more effective manner. }\end{array}$ & 3.81 & 1.04 \\
\hline
\end{tabular}

In analyzing this data, there are three findings that are of particular interest. Firstly, it is clear the students support the idea that the unit is and will be helpful in both their studies (70.6\%) and when they enter the IS industry (77.6\%). However, they do not support the idea that their experience in this unit will be helpful in their lives more generally (only $41.2 \%$ ). Second, students seem to be indicating that their experience

Table 4: Negative, positive and neutral percentages for each question

\begin{tabular}{|c|c|c|c|}
\cline { 2 - 4 } \multicolumn{1}{c|}{} & Negative & Neutral & Positive \\
\hline Q12 & $10.6 \%$ & $18.8 \%$ & $70.6 \%$ \\
\hline Q14 & $9.4 \%$ & $12.9 \%$ & $77.6 \%$ \\
\hline Q15 & $14.1 \%$ & $29.4 \%$ & $56.5 \%$ \\
\hline Q16 & 14.1 & $11.8 \%$ & $74.1 \%$ \\
\hline
\end{tabular}


in the unit has had a greater positive impact on their ability to analyze others' points of view (74.1\%) than it has had on their ability to better express their own reasoning to others $(56.5 \%)$.

It is interesting to note that this trend is found if we look at the data by gender, by domestic/international and by age group. Three graphs depicting the mean values for the different groups are shown in Figures 1,2 and 3 .

In Figure 1, we can also see that the females' experiences were consistently more positive than their male counterparts.

The experiences of the International students were also more positive than their Australian domestic counterparts as shown in Figure 2.

Age did not seem to play as much of a difference although there is some indication that the more mature students found the unit more positive.

\section{Lecturers' Reflections}

As indicated previously, the majority of students indicated that Reasoning and Critical Thinking had helped them in their studies either 'Quite a lot' or 'A lot'. Although there was some anecdotal evidence apparent to the lecturers in Melbourne and Brisbane to indicate an improvement in the quality of work submitted by students in Systems Analysis and Design and Programming Techniques 1, units concurrently undertaken by students enrolled in Reasoning and Critical Thinking for IS Professionals, the types and forms of assessment did not allow for a more direct relationship to be established.

While the students were overwhelmingly positive about the unit, the lecturers feel that there is room for growth and development. All the lecturers have concerns about the unit and its delivery and feel that these concerns need to be addressed in subsequent offerings of the unit.

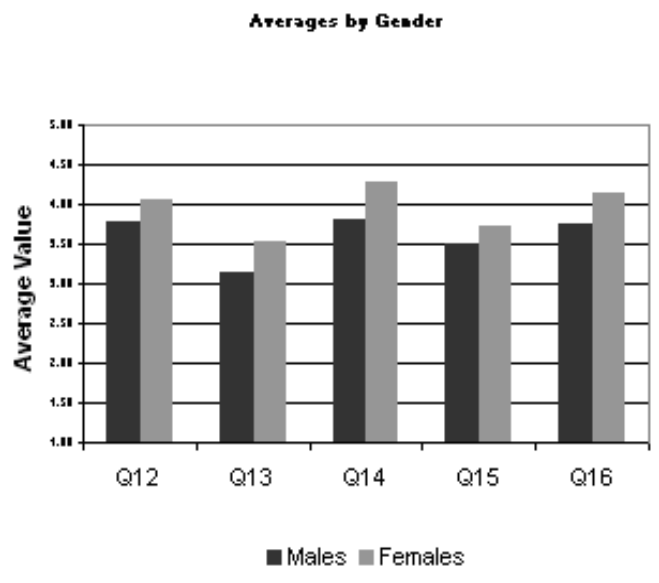

Figure 1: Average for questions by gender

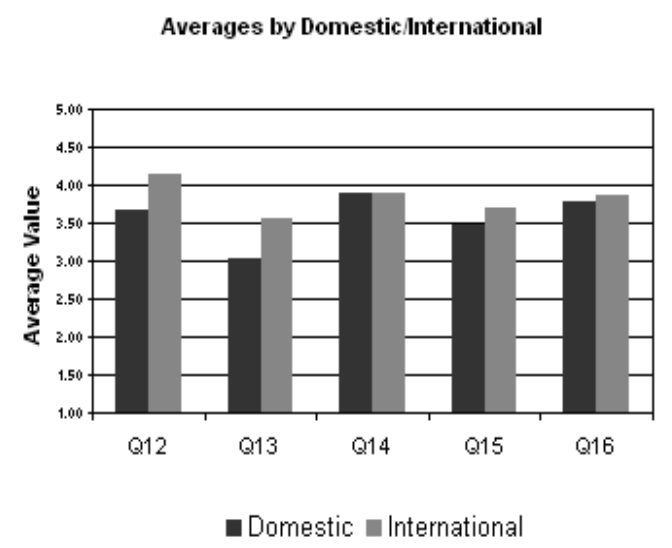

Figure 2: Averages for questions by domestic/international

Averages by age

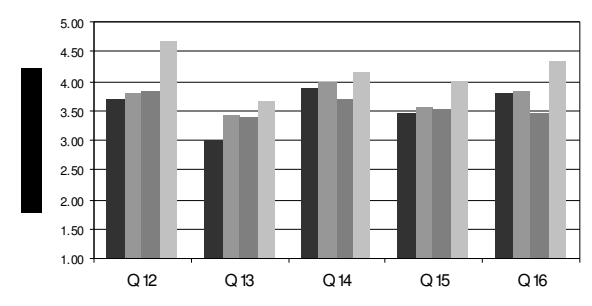

$17-20 \square 21-23 \square 24-26 \square>27$

Figure 3: Averages for questions by age 
In general, the lecturers concluded that the unit worked quite well in giving the students a broad idea of how the different thinking skills could be used within the field of IS. In the course of the semester, the lecturers presented diverse aspects of relevant thinking skills from analytical thinking in algorithm design and testing, through to systems thinking and even ethical thinking within IS. They had concerns however, about the depth to which the unit covered these areas.

This concern about depth is also indicated by the students' responses. As has been noted, the students could see how the skills could be useful to them in their studies and in the professional lives, but they were less sure of how the skills could help them in their day-to-day lives. This was evident in all three states and across all the different types of students, male and female, international or Australian, young to mature-age. On the other hand, there were also those students who commented on some of the exercises and methods used for the teaching of critical thinking skills, reasoning and claims as well as logic, saying that they could not see how these skills were relevant in IS.

Lecturers felt that the whilst students need to see the relevance of what they are doing in their professional and student life, but they also need to see its relevance in their day-to-day life. All the lecturers feel that these sections of the curriculum need to be investigated more thoroughly and that new exercises and tutorials must be developed in order to help the students develop these skills and see their relevance in all aspects of their lives.

Students' experiences of part of the unit that was intended to help them to analyze a problem, break it down into pseudocode, create test data and test that code differed from campus to campus because of the differences in how computer programming was taught on the three campuses. It was interesting to note, however, that even in Brisbane, where these techniques were taught in the two units, more students attempted the algorithm development question in the examination for the Reasoning and Critical Thinking unit than in the Programming unit. The fact that the two units are taught at the same time should be a help to the students and not a hindrance. In future, the lecturers intend to liaise with the Programming lecturer to ensure that the skills learnt in the one unit are practiced in the other. This will encourage the students to learn how to transfer their thinking skills to other relevant situations.

The process of peer review of assignments was found to be time consuming but worthwhile. The students realized and commented on its benefits. The lecturers also found this approach to assessment beneficial and are prepared to use this method of doing assignments in other units that they were teaching. The peer review process was thought to be particularly appropriate for learning how to write, test and maintain algorithms and computer programs as well as writing essays in other units.

Lecturers found that teaching from course notes and readings only is a problem. Generally, course notes do not give the depth that is needed in a particular topic. The problem with this unit, however, is that its scope is intended to be broad. In the next offering of the unit, the lecturers intend to include chapters from a variety of different books rather than use a definitive text. The tentative solution is to set up a good set of references in the libraries on each campus where the unit is offered and to use links to articles and materials on the web from WebCT. This will, hopefully, give the lecturers the flexibility they desire in a unit such as this.

The next planned step in the process is to determine how the students can be helped to practice the skills that they have learnt in other units. This can really only be done with the help of the lecturers who teach second and third year units. Possibilities for recruiting such support include the presentation of a workshop with lecturers to show them what has been done and give them ideas as to how to help students implement their skills. Another idea under consideration is to develop a written document that can be given to lecturers to help them to evaluate their assessment methods and ensure that they are addressing the fostering of thinking skills in their students. 


\section{Conclusion}

This paper has described the initial implementation of a unit introduced to develop the reasoning and critical thinking skills of first year university students in an Information Systems degree programme. This paper does not suggest that an IS students' reasoning and critical thinking skills should only be developed using a first year unit. Rather, the skills learnt in this unit will need to be practiced and applied in many different units throughout the students' course, otherwise it will be ineffective.

Future analysis of the students' work in this and other units will help us to determine whether or not the skills that they have learnt in this unit are able to be carried across to other units within the course and to their further studies at university.

\section{Acknowledgements}

We would like to thank our students; particularly those who have agreed to let us make use of their comments and assignments from this and other units.

\section{References}

ACU. (2002). Bachelor of Information Systems, Course Proposal and curriculum plan, Review, 2002. Australian Catholic University.

Allen, M. (1997). Smart thinking: Skills for critical understanding and writing. Melbourne, Australia: Oxford University Press, Australia.

Australian Government. (2003). Higher education statistics collection, Students 2003 (First Half Year): Selected higher education statistics - Retrieved: November 24, 2003, from http://www.dest.gov.au/highered/statistics/students/03/tables.htm

Bowles, R. (n.d.). More critical reasoning questions. Retrieved: August 19, 2003, from http://richardbowles.tripod.com/gmat/critreas/critreas.htm

de Bono, E. (1985). de Bono's thinking course. New York: Facts on File Publications.

de Bono, E. (1976). Teaching thinking. London: Maurice Temple Smith.

Gorgone, J., Davis, G., Valacich, J., Topi, H., Feinstein, D., \& Longenecker, H. (2002). IS 2002 - Model curriculum and guidelines for undergraduate degree programs in information systems. Association for Information Systems. Retrieved from http://www.acm.org/education/is2002.pdf

Goyal, A. (1995/1996 Winter). Enhancing student creativity in information systems education: The active learning approach. Journal of Information Systems Education, p.135.

Johnson, D., Johnson, R. \& Smith, K. (1997). Academic controversy: Enriching college instruction through instructional conflict. Josse-Basse.

Jones, H.M. (1997). An introduction to critical thinking. Riverwoord, NSW, Australia: Social Science Press.

MD 703: Primer on ethical reasoning with information technology. (n.d.). Retrieved: August 2, 2003, from http://www2.bc.edu/ fichman/703_Primer_on_Computer_Ethics.doc

Kolb, D. (1984). Experiential learning: Experience as the source of learning and development. Englewood Cliffs, NJ: Prentice-Hall.

Monk, A.F. \& Howard, S. (1998). The rich picture: a tool for reasoning about work context. Interactions, 5 (2), 21-30.

Nelson. (2002). Higher education at the crossroads: An overview paper. Commonwealth of Australia, Department of Education, Science and Training. 
Overstreet, K. (1999). Faked moon landings? Retrieved from http://batesmotel.8m.com/

Paul, R. \& Elder, L. (2002). Critical Thinking: Teaching students how to study and learn (part 1). Journal of Developmental Education, 26 (1), p.36.

Schön, D. A. (1983). The reflective practitioner: How professionals think in action. New York: Basic Books.

Schön, D. A (1987). Educating the reflective practitioner: Towards a new design for teaching and learning in the professions. San Francisco: Jossey-Bass.

Smith, F. (1992). To think: In language, learning and education. London: Routledge.

Wood-Harper, T., Corder, S. \& Byrne, B. (1999). Ethically situated information systems development. Proceedings of Australian Institute of Computer Ethics Conference. Lilydale, 1999. Retrieved from http://www.businessit.bf.rmit.edu.au/aice/events/AICEC99/papers1/WOO99036.pdf

Yates, K. (n.d.). Apollo moon landings: A resource for understanding the hoax claims. Retrieved from http://www.spacecentre.co.uk/images/apollomoonlandings.pdf

\section{Biographies}

Theda Thomas has been senior lecturer at the Melbourne campus of ACU National for the last two years. Previously she was Head of the Department of Business Information Systems at the Port Elizabeth Technikon in South Africa. She has been lecturing in the Information Systems area at tertiary level for 16 years. Her special area of research interest is Information Systems education and in particular developing methods of helping students develop the social, interpersonal and other non-technical skills that they would need in their professional life. Her PhD was completed in 2000 at the University of Pretoria and investigated how Joint Application Development Techniques could be used to develop the interpersonal and communication skills of IS students.

Tim Davis has been a senior lecturer at the Brisbane campus of ACU National for the last two years. Previously he was Head of the School of Information Technology at the University of New England Brisbane Centre. He has been lecturing in the Information Systems area for the past 15 years and his special area of research interest is in knowledge/learning technologies and selflearning. He is currently investigating the design and use of formal ontologies in the development of online self-constructing engagement learning systems.

Alanah Kazlauskas has been lecturing at the Sydney campus of ACU National since 1989. Her previous experience in introducing computers in schools led to Alanah's move to the tertiary education sector where she initially taught and developed computing courses offered by the School of Education to pre-service primary and secondary school teachers. Alanah moved to the Information Systems area in the mid-1990s with the development of the Information Systems by the School of Arts and Sciences. She has a strong interest in student learning and professional development. Alanah's doctoral research is currently investigating the dynamics of international scientific expert work in the non-profit sector. 